\title{
MANAGEMENT OF PATIENTS WITH CARDIAC IMPLANTABLE ELECTRONIC DEVICES UNDERGOING MAGNETIC RESONANCE IMAGING - PROPOSAL FOR UNIFIED HOSPITAL PROTOCOL: CROATIAN WORKING GROUP ON ARRHYTHMIAS AND CARDIAC PACING
}

\author{
Nikola Pavlović ${ }^{1}$, Kristijan Đula ${ }^{1}$, Ivan Kuharić 2 , Sandro Brusich ${ }^{3}$, Vedran Velagić ${ }^{4}$, \\ Zrinka Jurišić ${ }^{5}, Z_{\text {oran }}$ Bakotić $^{6}$, Ante Anić ${ }^{5}$, Borka Pezo Nikolić ${ }^{4}$, Vjekoslav Radeljić ${ }^{1}$, \\ Zlatko Cubranić ${ }^{3}$, Ivan Zeljković ${ }^{1}$, Dijana Zadravec ${ }^{2}$ and Šime Manola ${ }^{1}$ \\ ${ }^{1}$ Department of Cardiology, Sestre milosrdnice University Hospital Centre, Zagreb, Croatia; \\ ${ }^{2}$ Department of Radiology, Sestre milosrdnice University Hospital Centre, Zagreb, Croatia; \\ ${ }^{3}$ Department of Cardiology, Rijeka University Hospital Centre, Rijeka, Croatia; \\ ${ }^{4}$ Department of Cardiology, Zagreb University Hospital Centre, Zagreb, Croatia; \\ ${ }^{5}$ Department of Cardiology, Split University Hospital Centre, Split, Croatia; \\ ${ }^{6}$ Department of Cardiology, Zadar General Hospital, Zadar, Croatia
}

\begin{abstract}
SUMMARY - For many years, magnetic resonance imaging (MRI) was contraindicated in patients with cardiac implantable electronic devices (CIED). Today, there is a growing amount of evidence that MRI can be performed safely in the majority of patients with CIEDs. Firstly, there are devices considered MRI conditional by manufacturers that are available on the market and secondly, there is clear evidence that even patients with MRI non-conditional devices can also undergo MRI safely. Protocols have been developed and recommendations from different cardiac and radiologic societies have been published in recent years. However, the majority of physicians are still reluctant to refer these patients to MRI. Therefore, this document is published as a joint statement of the Croatian Working Group on Arrhythmias and Cardiac Pacing and Department of Radiology, Sestre milosrdnice University Hospital Centre to guide and ease the management of patients with CIED undergoing MRI. Also, we propose a unified protocol and checklist that could be used in Croatian hospitals.
\end{abstract}

Key words: Magnetic resonance imaging; Croatia; Heart; Pacemaker, artificial

\section{Introduction}

For years, it was considered that magnetic resonance imaging (MRI) is not a diagnostic option in patients with cardiac implantable electronic devices (CIEDs). The main reason was fear of adverse events potentially caused by exposing CIEDs to magnetic

Correspondence to: Nikola Pavlovic, MD, PhD FESC,FEHRA Sestre milosrdnice University Hospital Centre, Department of Cardiology, Vinogradska c. 29, HR-10000 Zagreb, Croatia

E-mail: nikolap12@yahoo.com

Received April 23, 2019, accepted June 14, 2019 field, especially inhibition of pacing, tissue and/or lead overheating, or inappropriate defibrillator shocks. Epidemiological data show that almost $75 \%$ of patients with CIED will have an indication for MRI during their lifetime ${ }^{1}$. With the increasing number of patients being implanted with $\mathrm{CIEDs}^{2,3}$, in some of whom MRI may not be adequately replaced by other diagnostic imaging, there is the need for a standardized protocol for MRI imaging in these patients. Today, numerous studies have shown that it is possible and safe to use MRI in the large majority of CIED patients even up to $3 \mathrm{~T}^{4-7}$. The aim of this document is to 
standardize protocols for MRI in CIED patients and to allow for safe imaging in the majority of patients.

This document is based on the current European, American and Canadian guidelines ${ }^{8-10}$ published in recent years. The current document is published as a joint statement of the Croatian Working Group on Arrhythmias and Cardiac Pacing and Department of Radiology, Sestre milosrdnice University Hospital Centre.

\section{Potential Risks of Magnetic Resonance Imaging}

The potential risks of MRI scanners in patients with CIED arise from magnetic fields (both static and gradient) and from radiofrequency fields ${ }^{8}$. This can cause heating, mechanical pull, torque and vibration, as well as electrical current generation or electrical stimulation ${ }^{11}$. Special concerns are heating of the leads, induction of current in conductive wires causing thermal tissue injury, effect on reed-switch activity, electromagnetic interference (EMI), oversensing of MRI-generated signals causing inhibition of pacing and inappro-

Table 1. Potential risks of MRI in patients with implanted cardiac devices

Potential concerns about MRI in patients with CIEDs

1. Potential device movement, mainly generator (leads do not contain significant amount of ferromagnetic materials), but rarely due to subcutaneous position ('pocket')

2. Induced electrical current in leads that can trigger different atrial or ventricular arrhythmias

3. Thermal injury of myocardium due to RF energy exposure and consequently heating of the leads

4. Reed switch phenomena - mimicking of superficial magnet placement on device resulting in asynchronous pacing mode or inhibition of anti-tachycardia therapies

5. Electromagnetic interference (EMI) causes oversensing phenomena and subsequent inappropriate inhibition of pacing or inappropriate shocks

6. Power-on-reset - backup programming mode that resets CIED (variation depends on manufacturer, type, etc.), caused by EMI

7. Imaging artifacts

MRI = magnetic resonance imaging; CIED = cardiac implantable electronic device; $\mathrm{RF}$ = radiofrequency priate defibrillator shocks. Table 1 shows the potential MRI effects on CIEDs.

Finally, imaging artifacts can develop during MRI in patients with CIED, which can influence image interpretation. These artifacts depend on the device size, position, scanning protocol and imaging plane.

\section{Types of Devices}

Cardiac implantable electronic devices can be categorized as MRI safe, MRI conditional, MRI nonconditional and MRI unsafe. The majority of CIEDs are either MRI conditional or MRI non-conditional. MRI conditional CIED means that the device has no known hazards in specified MR environment. It is important to note that a MRI conditional device has all components (generator, leads) which are MRI conditional. If one part is non-conditional, the system is automatically MRI non-conditional ${ }^{8}$.

The MRI non-conditional devices include all devices that do not fulfill the previously mentioned criteria or have never been evaluated or tested in MR environment. Also, devices in patients that do not meet all the specified conditions of use, such as patients with abandoned leads, are considered to be MRI non-conditional ${ }^{8}$. MRI safe labeling means that there is no hazard in MR environment. No CIED has MRI safe labeling. MRI unsafe CIEDs are those in which MRI can or will cause harm, such as patients with abandoned, fractured or epicardial leads.

\section{Absolute Contraindications}

The absolute contraindications for performing MRI in CIEDs are the presence of epicardial, fractured and abandoned intracardiac leads. Although some in vitro studies have shown increased heating of these leads with consequently thermal tissue injury, later observations did not confirm $i^{12}{ }^{12}$. Until larger studies confirm the safety of MRI in these situations, they remain an absolute contraindication for MRI.

\section{Current Data}

Several small observational studies and case series were performed in the 1980s and 1990s claiming that MRI can be safely performed in non-conditional MRI 
devices. Nazarian et al. ${ }^{4}$ report results from a prospective, nonrandomized study which included $1509 \mathrm{pa}^{-}$ tients with a total of 2019 performed 1.5T MRIs. They found no significant adverse effects in all patients that underwent MRI scans while MRI was not completed in two patients, one due to sensation in the chest and another one because of transient loss of pacing due to electrical reset. Only in one case, pacemaker could not be interrogated after a MRI, which was a pacemaker with almost depleted battery (less than 1 month estimated replacement interval) and was subsequently replaced.

Simultaneously, a large multicenter, prospective registry MagnaSafe was conducted and included 1000 patients with conventional pacemakers and $500 \mathrm{pa}^{-}$ tients with implantable cardiac defibrillators (ICDs), which confirmed these findings ${ }^{5}$. Patients underwent pre-MRI device interrogation, monitoring during MRI, and post-MRI device interrogation. Patients requiring thoracic scans were excluded from this registry. No deaths, lead failures, loss of capture or ventricular arrhythmias occurred. Six (0.4\%) patients experienced atrial arrhythmias during MRI and six (0.4\%) patients experienced partial generator electrical reset.

Based on these data, several societies have published their recommendations. In 2013, the European Society of Cardiology (ESC) Guidelines on cardiac pacing have already published their protocol for the management of patients with MRI non-conditional devices ${ }^{11}$. Later in 2014, the Canadian and in 2017 the Heart Rhythm Society (HRS) published detailed and thorough recommendations for the management of these patients ${ }^{8,12}$.

Lately, observational studies suggesting that $3 \mathrm{~T}$ MRIs are safe and feasible in patients with CIEDs have been published, however, prospective and larger studies are needed before 3T MRIs could be widely performed in patients with CIEDs $s^{6,7}$.

Although it seems reasonable to apply the same protocols for MRI in children with CIEDs, it should be noted that patients younger than 18 years have been excluded from most of the MRI studies. Infants and young children also frequently undergo implants of epicardial systems rendering any MRI contraindicated. There are many case series suggesting that MRIs can be safely performed in children, however, due to limited data, MRI conditional systems should be preferred in these patients ${ }^{8}$.

\section{Protocol}

In order to help clinicians, especially cardiologists and radiologists, in their everyday routine, several cardiac and radiologic societies have published guidelines/recommendations for the management of $\mathrm{pa}^{-}$ tients with CIEDs undergoing MRI. The goal was to simplify and unify the approach while ensuring safety of these patients.

Before performing any of MRI procedures, clinical benefits and possible harms that can be caused should be evaluated. Compelling indication for MRI with no other imaging method available should be confirmed.

At the site where MRI is performed, defibrillators with external pacing function, continuous cardiac monitoring and pulse oximetry should be available. Medical personnel on site should be able to provide advanced life support.

To achieve good workflow, it is recommended to introduce local institutional protocols, developed by cardiology and radiology experts, that will consist of patient data such as manufacturer of CIED, indication for primo-implantation, types of generators and lead, stimulation parameters, etc.

If MRI is planned in a patient with MRI compatible devices (list on http://www.mrisafety.com/), it is advisable to adhere to all manufacturer's instructions.

In patients with non-conditional MRI devices, stimulation parameters (battery, sensing, impedance, threshold) should be tested prior to MRI. The presence of epicardial, fractured or abandoned leads should be excluded, since they represent absolute contraindications for MRI. These can be evaluated based on the patient's hospital records or by performing simple chest $\mathrm{x}$-ray.

After testing the CIED, further programming depends on whether the patient is dependent on cardiac pacing. If the patients are pacemaker dependent then the device should be programmed to asynchronous mode of stimulation (VOO/DOO). If the patient is not dependent, then the pacemaker should be programmed to VVI od DDD mode of stimulation. In addition, in all patients, other pacemaker functions such as rate responsiveness or noise determination have to be turned off. In patients with ICDs, detection/therapy of tachycardias should be turned off to prevent inappropriate shocks. All patients who are pacemaker dependent or have ICDs, should be moni- 


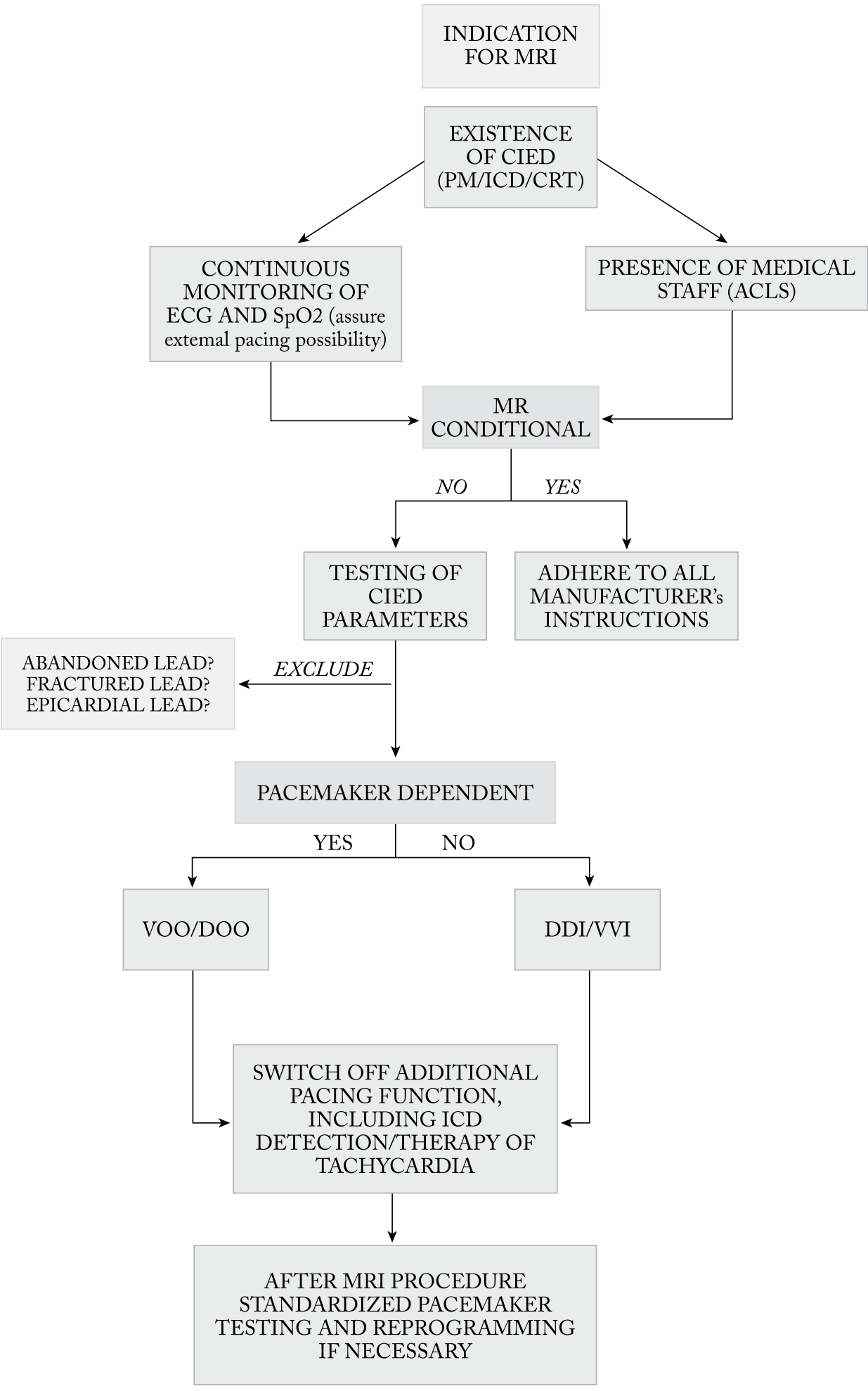

Fig. 1. Algorithm for management of patients with CIEDs.

$\mathrm{CIED}=$ cardiac implantable electronic device; $\mathrm{MRI}=$ magnetic resonance imaging; $\mathrm{PM}=$ conventional pacemaker; $\mathrm{ICD}=$ implantable cardioverter defibrillator; $\mathrm{CRT}=$ cardiac resynchronization therapy; $\mathrm{ECG}=$ electrocardiogram; $\mathrm{SpO} 2=$ oxygen saturation; $\mathrm{ACLS}=$ advanced cardiovascular life support 
Name/Surname

\section{DEVICE}

\section{PM}

CRT

ICD

MRI conditional device?

Programmed according to manufacturer?

Does the patient have abandoned, fractured or epicardial lead?

Has chest $\mathrm{x}$-ray been performed?

Is chest $x$-ray indicated?

Are there absolute contraindications for MRI present?

\section{RADIOLOGIST}

Does the pt have indication for MRI?

MR 1.5 T

Is there other imaging method to confirm diagnosis that can be used instead of MRI?

Signature:

\section{DEVICETESTING}

Inhibition:

Is the pt PM dependent?

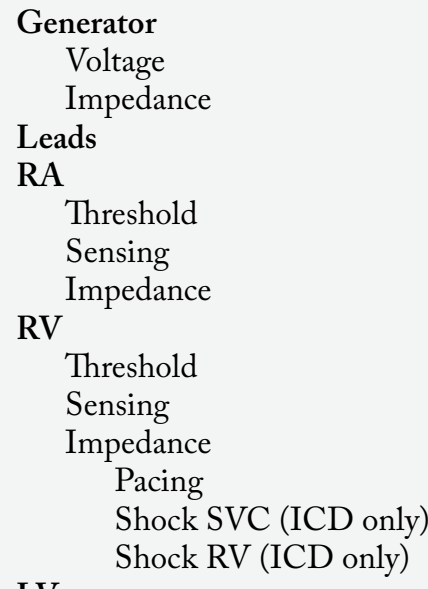

$$
\begin{aligned}
& \text { Threshold } \\
& \text { Sensing } \\
& \text { Impedance }
\end{aligned}
$$

MANUFACTURER

Date of birth

YES $\square$
YES $\square$
YES $\square$
YES $\square$
YES $\square$
YES $\square$

$\begin{array}{ll}\text { NO } & \\ \text { NO } & \\ \text { NO } & \\ \text { NO } & \\ \text { NO } & \\ \text { NO } & \end{array}$

YES

YES

YES

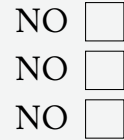

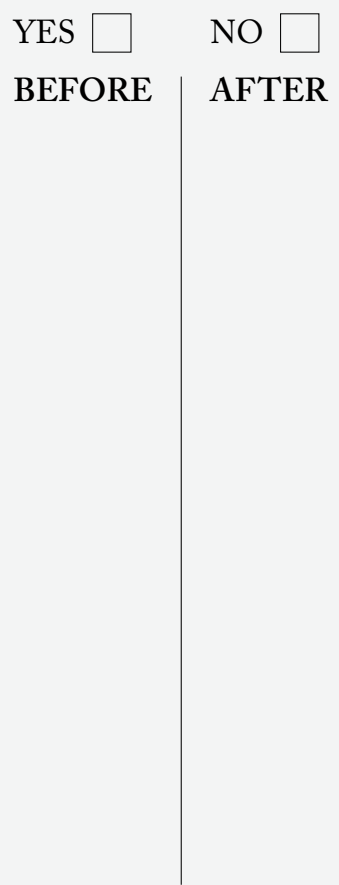

AFTER

Programming

BEFORE

Signature:

Fig. 2. Proposed hospital checklist for patients with CIEDs undergoing MRI.

$\mathrm{CIED}=$ cardiac implantable electronic device; $\mathrm{MRI}=$ magnetic resonance imaging; $\mathrm{PM}=$ conventional pacemaker; $\mathrm{ICD}=$ implantable cardioverter defibrillator; $\mathrm{CRT}=$ cardiac resynchronization therapy; $\mathrm{ECG}=$ electrocardiogram; $\mathrm{Pt}=$ patient; $\mathrm{RA}=$ right atrium; $\mathrm{RV}=$ right ventricle; $\mathrm{LV}=$ left ventricle; $\mathrm{SVC}$ = superior vena cava 
tored during transport to MRI and back. Upon completion of MRI, pacemakers should be retested and reprogrammed to original parameters.

The protocol and the hospital checklist are shown in Figures 1 and 2.

Recently, Blissett et al. published 5 key aspects when performing MRI in CIED patients ${ }^{13}$ :

1) prior to MRI, the risk-benefit ratio should be established. Clear indication for MRI should be established;

2) conditionality of CIED can be established from manufacturer's data or checking on MRIsafety.org. Currently, non-conditional devices can undergo MRI following certain protocols and if there are no fractured, abandoned or epicardial leads;

3) all patients should undergo pre- and post-MRI device interrogation, as well as 3- and 6-month follow-ups;

4) during an MRI, patients with pacemakers should be programmed to asynchronous mode if dependent on pacing. In patients with ICDs, detection and therapies should be turned off. All other advanced functions should be deactivated; and

5) during an MRI, patients who are pacemaker dependent or have an ICD should be monitored with an electronic control device and/or pulse oximetry. External defibrillator with pacing function should be available. In patients with ventricular arrhythmias or in patients with nonconditional devices who are pacing dependent, personnel capable of programming CIEDs need to be available.

\section{Conclusion}

Today, MRI can be performed safely in a vast majority of CIED patients, both with conditional and nonconditional CIEDs, if strict protocols are followed. This requires collaboration between cardiologists and radiologists. Based on the current data and guidelines available, we propose the protocol and checklist for the management of these patients in Croatia.

\section{References}

1. Kalin R, Stanton MS. Current clinical issues for MRI scanning of pacemaker and defibrillator patients. Pacing Clin Electro- physiol PACE. 2005 Apr;28(4):326-8. doi: 10.1111/j.15408159.2005.50024.x

2. Pavlović N, Manola Š, Vražić H, Vučić M, Brusich S, Radeljić V, et al. Recommendations for perioperative management of patients with cardiac implantable electronic devices. Acta Clin Croat. 2018 Jun;57(2):383-90. doi: 10.20471/acc.2018.57.02.22.

3. Brusich S, Zeljković I, Pavlović N, Anić A, Jurišić Z, Židan D, et al. Croatian national data and comparison with European practice: data from the Cardiac Resynchronization Therapy Survey II Multicenter Registry. Cardiol Res Pract. 2018; 2018:3479846. doi: 10.1155/2018/3479846.

4. Nazarian S, Hansford R, Rahsepar AA, Weltin V, McVeigh D, Gucuk Ipek E, et al. Safety of magnetic resonance imaging in patients with cardiac devices. N Eng1 J Med. 2017;377(26): 2555-64. doi: 10.1056/NEJMoa1604267.

5. Russo RJ, Costa HS, Silva PD, Anderson JL, Arshad A, Biederman RWW, et al. Assessing the risks associated with MRI in patients with a pacemaker or defibrillator. N Engl J Med. 2017;376(8):755-64. doi: 10.1056/NEJMoa1603265.

6. van Dijk VF, Delnoy PPHM, Smit JJJ, Ramdat Misier RA, Elvan A, van Es HW, et al. Preliminary findings on the safety of 1.5 and 3 Tesla magnetic resonance imaging in cardiac pacemaker patients. J Cardiovasc Electrophysiol. 2017 Jul;28(7): 806-10. doi: 10.1111/jce.13231

7. Naehle CP, Meyer C, Thomas D, Remerie S, Krautmacher C, Litt H, et al. Safety of brain 3-T MR imaging with transmitreceive head coil in patients with cardiac pacemakers: pilot prospective study with 51 examinations. Radiology. 2008 Dec; 249(3):991-1001. doi: 10.1148/radiol.2493072195.

8. Indik JH, Gimbel JR, Abe H, Alkmim-Teixeira R, Birgersdotter-Green U, Clarke GD, et al. 2017 HRS Expert consensus statement on magnetic resonance imaging and radiation exposure in patients with cardiovascular implantable electronic devices. Heart Rhythm. 2017;14(7):e97-153. doi: 10.1016/j. hrthm.2017.04.025. Epub 2017 May 11.

9. Brignole M, Auricchio A, Baron-Esquivias G, Bordachar P, Boriani G, Breithardt O-A, et al. 2013 ESC Guidelines on cardiac pacing and cardiac resynchronization therapy: the Task Force on cardiac pacing and resynchronization therapy of the European Society of Cardiology (ESC). Developed in collaboration with the European Heart Rhythm Association (EHRA). Eur Heart J. 2013 Aug;34(29):2281-329. doi: 10.1093/europace/eut206. Epub 2013 Jun 24

10. Verma A,Ha ACT, Dennie C, Essebag V, Exner DV, Khan N, et al. Canadian Heart Rhythm Society and Canadian Association of Radiologists consensus statement on magnetic resonance imaging with cardiac implantable electronic devices. Can J Cardiol. 2014 Oct;30(10):1131-41. doi: 10.1016/j.cjca.2014. 07.010.

11. Nordbeck P, Weiss I, Ehses P, Ritter O, Warmuth M, Fidler F, et al. Measuring RF-induced currents inside implants: impact of device configuration on MRI safety of cardiac pacemaker leads. Magn Reson Med.2009 Mar;61(3):570-8. doi: 10.1002/ mrm.21881. 
12. Strach K, Naehle CP, Mühlsteffen A, Hinz M, Bernstein A, Thomas D, et al. Low-field magnetic resonance imaging: increased safety for pacemaker patients? Europace. 2010 Jul;12 (7):952-60. doi: 10.1093/europace/euq081. Epub 2010 Mar 31.;12(7):952-60.
13. Blissett S, Chetrit M, Kovacina B, Mardigyan V, Afilalo J. Performing cardiac magnetic resonance imaging in patients with cardiac implantable electronic devices: a contemporary review. Can J Cardiol. 2018 Dec;34(12):1682-6. doi: 10.1016/j.cjca. 2018.09.009. Epub 2018 Sep 29.

Sažetak

PREPORUKE ZA POSTUPANJE KOD BOLESNIKA SA SRČANIM IMPLANTABILNIM

ELEKTRONIČKIM UREĐAJIMA KOJI SU PODVRGNUTI MAGNETSKOJ REZONANCI

- RADNA SKUPINA ZA ARITMIJE I ELEKTROSTIMULACIJU HRVATSKOGA KARDIOLOŠKOG DRUŠTVA

\author{
N. Pavlovic, K. Đula, I. Kuharic, S. Brusich, V. Velagic, Z. Jurisici, Z. Bakotic, A. Anic, B. Pezo Nikolic, \\ V. Radeljic, Z. Čubranic, I. Zeljkovic, D. Zadravec i Š. Manola
}

Magnetska rezonanca (MR) dugo je bila kontraindicirana dijagnostička metoda kod bolesnika sa srčanim implantabilnim elektroničkim uređajima (CIED). Danas imamo dovoljno dokaza da se MR može sigurno učiniti kod većine bolesnika s CIED. Prvo, postoje uređaji koji mogu biti podvrgnuti MR prema preporukama proizvođača, a drugo, postoje jasni dokazi da većina uređaja koji nisu označeni kao sigurni za MR od proizvođača također mogu biti podvrgnuti MR. Tijekom godina razvijeni su brojni protokoli kardioloških i radioloških društava, međutim, dio liječnika i dalje oklijeva kod postavljanja indikacije za MR u ove skupine bolesnika. Stoga je Radna skupina za aritmije i elektrostimulaciju srca Hrvatskoga kardiološkog društva u suradnji s radiolozima KBC Sestre milosrdnice pripremila preporuke za postupanje s bolesnicima s CIED koji su podvrgnuti MR.

Ključne riječi: Magnetska rezonancija, snimanje; Hrvatska; Srce; Srčani elektrostimulator 